\title{
Expression of Excitatory Amino Acid Transporter Interacting Protein Transcripts in the Thalamus in Schizophrenia
}

\author{
IBONE HUERTA, ${ }^{1,3}$ ROBERT E. MCCULLUMSMITH, ${ }^{1 *}$ VAHRAM HAROUTUNIAN, ${ }^{2}$ \\ JOSÉ MANUEL GIMÉNEZ-AMAYA, ${ }^{3}$ AND JAMES H. MEADOR-WOODRUFF ${ }^{1}$ \\ ${ }^{1}$ Molecular and Behavioral Neuroscience Institute and Department of Psychiatry, \\ University of Michigan Medical School, Ann Arbor, Michigan 48109 \\ ${ }^{2}$ Department of Psychiatry, Mount Sinai School of Medicine, New York, New York 10029 \\ ${ }^{3}$ Departamento de Morfología, Facultad de Medicina Universidad Autónoma de Madrid, \\ 28029 Madrid, Spain
}

\begin{abstract}
KEYWORDS glutamate; in situ hybridization; postmortem; haloperidol; clozapine
ABSTRACT The excitatory amino acid transporters (EAATs) are a family of plasma membrane proteins that maintain synaptic glutamate concentration by removing glutamate from the synaptic cleft. EAATs are expressed by glia (EAAT1 and EAAT2) and neurons (EAAT3 and EAAT4) throughout the brain. Glutamate reuptake is regulated, in part, by EAAT-interacting proteins that modulate subcellular localization and glutamate transport activity of the EAATs. Several lines of investigation support the hypothesis of glutamatergic abnormalities in schizophrenia. Previous work in our laboratory demonstrated increased expression of EAAT1 and EAAT2 transcripts in the thalamus, suggesting that alterations in synaptic glutamate levels may contribute to the pathophysiology of schizophrenia. Since EAAT-interacting proteins regulate EAAT function, directly impacting glutamatergic neurotransmission, we hypothesized that expression of EAAT-interacting proteins may also be altered in schizophrenia. Using in situ hybridization in subjects with schizophrenia and a comparison group, we detected increased expression of JWA and KIAA0302, molecules that regulate EAAT3 and EAAT4, respectively, in the thalamus in schizophrenia. In contrast, we did not find changes in the expression of transcripts for the EAAT2 and EAAT4 regulatory proteins GPS-1 and ARHGEF11. To address prior antipsychotic treatment in our schizophrenic subjects, we treated rats with haloperidol and clozapine for 4 weeks, and found changes in transcript expression of the EAAT-interacting proteins in clozapine-, but not haloperidol-, treated rats. These findings suggest that proteins associated with the regulation of glutamate reuptake may be abnormal in this illness, supporting the hypothesis of altered thalamic glutamatergic neurotransmission in schizophrenia. Synapse 59:394-402, 2006. @ 2006 Wiley-Liss, Inc.
\end{abstract}

\section{INTRODUCTION}

The glutamate hypothesis of schizophrenia is based, in part, on the observation that phencyclidine, an NMDA receptor antagonist, can trigger schizophreniform symptoms in nonpsychotic subjects and exacerbate psychotic symptoms in schizophrenia (Itil et al., 1967; Lahti et al., 1995; Luby et al., 1962). Supporting this hypothesis, postmortem studies have revealed region-specific alterations in molecules involved in glutamate transmission in this illness. These findings include changes in the expression of ionotropic glutamate receptor subunits and glutamate transporters, suggesting that abnormalities in postsynaptic and presynaptic neurons, as well as glial cells, may contribute to the pathophysiology of schizophrenia (Harrison et al., 2003; Lewis et al., 2003; Meador-Woodruff et al., 2003; Scarr et al., 2005).

Glutamate is released from presynaptic neurons, activates glutamate receptors, and is then removed from the synapse by a family of plasma membrane

\footnotetext{
*Correspondence to: Robert E. McCullumsmith, 205 Zina Pitcher Place, Molecular and Behavioral Neuroscience Institute, University of Michigan, Ann Arbor, MI 48109, USA. E-mail: smithrob@umich.edu

Received 27 July 2005; Accepted 13 December 2005

DOI 10.1002/syn.20250

Published online in Wiley InterScience (www.interscience.wiley.com).
} 
proteins, the excitatory amino acid transporters (EAATs) (Bellocchio et al., 2000; Hollmann and Heinemann, 1994; Kanai et al., 1993; Rothstein et al., 1994). EAATs are expressed on astrocytes and Bergmann glia (EAAT1 and EAAT2) and in neurons (EAAT3 and EAAT4) throughout the brain (Danbolt, 2001). EAAT-mediated glutamate reuptake is regulated, in part, by several EAAT-interacting proteins (Danbolt, 2001; Jackson et al., 2001; Lin et al., 2001; Marie et al., 2002; Watanabe et al., 2003). EAATinteracting proteins utilize diverse mechanisms to modulate glutamate transport activity. The EAATinteracting proteins Ajuba and $G$ protein pathway suppressor-1 (GPS-1) were identified by the yeast two-hybrid technique using GLT-1 (the EAAT2 rodent isoform) as bait (Marie et al., 2002; Watanabe et al., 2003). Ajuba interacts with the amino terminus of GLT-1, is expressed in astrocytes and Bergmann glia, and may act as a scaffolding protein, linking GLT-1 with the cytoskeleton and various signaling pathways (Marie et al., 2002). GPS-1 is a subunit of COP9 signalosome, interacts with the $\mathrm{C}$ terminus of GLT-1, and may be involved in the surface trafficking of GLT-1 via its leucine zipper-like motif (Watanabe et al., 2003). Coexpression of GPS-1 with GLT-1 in human embryonic kidney cells downregulates glutamate reuptake activity (Watanabe et al., 2004).

Several proteins that interact with neuronal glutamate transporters have also been identified. JWA is the human homologue of GTRAP3-18, a protein that interacts with the carboxy terminus of EAAC1 (called EAAT3 in humans), decreasing EAAC1 activity by lowering transporter substrate affinity via a reduction of N-linked glycosylation (Butchbach et al., 2003; Lin et al., 2001; Ruggiero et al., 2003). Rodent EAAT4 interacts with GTRAP41 and GTRAP48. GTRAP41 links EAAT4 with the cytoskeleton, and GTRAP48 is a cytoplamatic protein associated with Rho-GTPase signaling. Coexpression of GTRAP41 or GTRAP48 with EAAT4 stabilizes EAAT4 localization at the synaptic membrane. GTRAP41 and GTRAP48 modulate the perisynaptic distribution of EAAT4 at glutamatergic synapses, and also upregulate glutamate transport into neurons (Jackson et al., 2001). The human homologues of GTRAP41 and GTRAP48, called KIAA0302 and ARHGEF11, are expressed in multiple brain regions, including the thalamus (unpublished observations).

The thalamus plays an important role in processing sensorimotor and cognitive information via its connections with cerebrocortical and subcortical regions. Disturbances of these functions in schizophrenia, together with structural and functional thalamic pathology, have implicated abnormalities in the thalamus in this illness. Magnetic resonance imaging and postmortem morphometric studies have found reduced volume of the thalamus in schizophrenia, as well as cell loss within thalamic nuclei connected with prefrontal cortex and limbic structures, in particular the dorsomedial, pulvinar, anterior and ventral lateral nuclei (Byne et al., 2002; Danos et al., 2003; Dorph-Petersen et al., 2004; Pakkenberg, 1992; Popken et al., 2000; Young et al., 2000). Functional imaging studies have also detected irregularities in thalamic nuclei, including reduced thalamic metabolism in subjects with schizophrenia (Andreasen et al., 1996; Buchsbaum and Hazlett, 1998; Buchsbaum et al., 1996; Hazlett et al., 1999). Other studies (Meador-Woodruff et al., 2003) have reported neurochemical abnormalities in glutamate transmission in the thalamus, including increased expression of EAAT1 and EAAT2 transcripts (Smith et al., 2001a), suggesting that alterations in synaptic glutamate levels may contribute to the pathophysiology of schizophrenia. Thus, we hypothesize that there may be alterations in the expression of molecules that regulate EAAT expression and glutamate reuptake activity. Accordingly, we investigated the expression of transcripts for the EAAT-interacting proteins Ajuba, GPS-1, JWA, KIAA0302, and ARHGEF11 in the thalamus in schizophrenia.

\section{MATERIALS AND METHODS Subjects}

A total of 21 subjects from the Mount Sinai Medical Center were studied in this project: 13 individuals diagnosed with schizophrenia and 8 control subjects with no history of psychiatric illness as previously described (Smith et al., 2001a,b) (Table I). Consent for autopsy and use of brain tissue for research was obtained from the legal next of kin of each donor. Subjects were diagnosed with schizophrenia when (1) the presence of schizophrenic symptoms could be documented before age 40; (2) the medical records contained evidence of psychotic symptoms and at least 10 years of psychiatric hospitalization with a diagnosis of schizophrenia; (3) the DSM-III-R diagnosis of schizophrenia was agreed upon by two experienced clinicians; and (4) neuropathological examination did not reveal Alzheimer's disease or other degenerative disorders. There were no significant differences between diagnostic groups for age, postmortem interval (PMI), sex, tissue $\mathrm{pH}$, or hemisphere studied. Brains were obtained after autopsy and one hemisphere was cut coronally into $1-\mathrm{cm}$ slabs and frozen. Sections $(20 \mu \mathrm{m})$ were thawed onto slides previously treated with poly-L-lysine, dried, and stored at $-80^{\circ} \mathrm{C}$. Two slides were studied per subject.

\section{In situ hybridization}

mRNA expression was measured by in situ hybridization using subclones that were generated by amplifying unique segments of GPS-1 (Genebank accession 
TABLE I. Demographic and clinical characteristics of the schizophrenic and comparison subjects examined postmortem for thalamic expression of EAAT interacting proteins

\begin{tabular}{|c|c|c|c|c|c|c|c|}
\hline Subject & Sex & Age & $\mathrm{PMI}^{\mathrm{a}}$ & $\mathrm{pH}$ & Side & Cause of death & Medication \\
\hline \multicolumn{8}{|c|}{ Control subjects } \\
\hline 1 & $\mathrm{~F}$ & 86 & 4.7 & 6.5 & Left & Unknown & None \\
\hline 2 & $\mathrm{M}$ & 70 & 8.0 & 6.0 & Left & Lower gastrointestinal bled & None \\
\hline 3 & $\mathrm{M}$ & 55 & 10 & 5.7 & Left & Lymphoma & None \\
\hline 4 & $\mathrm{~F}$ & 96 & 3.3 & 6.7 & Left & Cardiopulmonary failure & None \\
\hline 5 & $\mathrm{~F}$ & 90 & 4.2 & 6.0 & Left & Cardiopulmonary failure & None \\
\hline 6 & $\mathrm{~F}$ & 74 & 3 & 6.0 & Right & Cardiopulmonary failure & None \\
\hline 7 & $\mathrm{~F}$ & 82 & 3.8 & 5.8 & Left & Cardiopulmonary failure & None \\
\hline 8 & $\mathrm{~F}$ & 64 & 19.1 & 6.1 & Left & Cardiopulmonary failure & None \\
\hline Total $^{\mathrm{b}}$ & $6 \mathrm{~F} / 2 \mathrm{M}$ & $77.1 \pm 13.9$ & $7.3 \pm 5.4$ & $6.1 \pm 0.34$ & $7 \mathrm{~L} / 1 \mathrm{R}$ & & \\
\hline \multicolumn{8}{|c|}{ Schizophrenia subjects } \\
\hline 9 & $\mathrm{~F}$ & 86 & 6.9 & 6.2 & Right & Cardiac failure, pneumonia & None $^{c}$ \\
\hline 10 & $\mathrm{M}$ & 61 & 3.5 & 6.5 & Left & Cardiac failure & Trilafon \\
\hline 11 & $\mathrm{M}$ & 69 & 4.5 & 6.4 & Right & Myocardial infarction & Haloperidol \\
\hline 12 & $\mathrm{M}$ & 72 & 20.6 & 6.6 & Left & Cardiopulmonary failure & Haloperidol \\
\hline 13 & $\mathrm{M}$ & 63 & 6.2 & 5.9 & Left & Cardiopulmonary failure & Haloperidol \\
\hline 14 & $\mathrm{~F}$ & 69 & 13.7 & 6.2 & Left & Cardiopulmonary failure & Haloperidol \\
\hline 15 & $\mathrm{M}$ & 68 & 5.6 & 6.8 & Left & Cardiopulmonary failure & Haloperidol \\
\hline 16 & $\mathrm{~F}$ & 64 & 6.5 & 6.6 & Left & Cardiopulmonary failure & Haloperidol \\
\hline 17 & $\mathrm{M}$ & 61 & 2.8 & 6.4 & Left & Cardiac failure & Thioridazine \\
\hline 18 & $\mathrm{~F}$ & 73 & 10.4 & 6.3 & Right & Cardiopulmonary failure & Typical antipsychotic \\
\hline 19 & $\mathrm{M}$ & 66 & 12.1 & 6.5 & Left & Cardiac failure & None $\mathrm{d}^{\mathrm{d}}$ \\
\hline 20 & $\mathrm{~F}$ & 76 & 21.2 & 6.1 & Right & Cardiac failure & Haloperidol \\
\hline 21 & $\mathrm{~F}$ & 100 & 4.6 & 6.6 & Left & Cardiogenic shock & None $\mathrm{d}^{\mathrm{d}}$ \\
\hline Total $^{\mathrm{b}}$ & $6 \mathrm{~F} / 7 \mathrm{M}$ & $69.8 \pm 7.4$ & $10.4 \pm 6.6$ & $6.4 \pm 0.32$ & $9 \mathrm{~L} / 4 \mathrm{R}$ & & \\
\hline
\end{tabular}

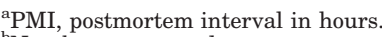

${ }^{\mathrm{b}}$ Numbers expressed as mean \pm standard deviation.

${ }^{\mathrm{c}}$ None for 8 years prior to death.

${ }^{\mathrm{d}}$ None in last 6 months prior to death.

no. BC064503; nucleotide coding region 1396-1602), Ajuba (BC007580; 114-1354), JWA (NM006407; 181520), KIAA0302 (AB008567; 5958-6345), and ARHGEF11 (NM014784; 1935-2309), from a human cDNA brain library (Human Adult Brain Unamplified cDNA Library, Edge Biosystems; Gaithersburg, MD) and by polymerase chain reaction (PCR). PCR-amplified cDNA segments were extracted (QIAquick Gel Extraction Kit, Qiagen, Valencia, CA), subcloned (Zero Blunt TOPO PCR cloning kit; Invitrogen, Carlsbad, CA), and confirmed by nucleotide sequencing.

Sense and antisense probes for in situ hybridization were synthesized using $100 \mu \mathrm{Ci}$ of dried $\left[{ }^{35} \mathrm{~S}\right] \mathrm{UTP}$; $2.0 \mu \mathrm{l}$ of $5 \times$ transcription buffer (40 mM Tris-base, $6 \mathrm{mM} \mathrm{MgCl}_{2}, 2 \mathrm{mM}$ spermidine,10 mM NACl, pH7.9); $1.0 \mu \mathrm{l}$ each of $10 \mathrm{mM}$ ATP, CTP, and GTP; $1.0 \mu \mathrm{g}$ linearized plasmid DNA; $0.5 \mu$ RNAse inhibitor; and $1.5 \mu \mathrm{SP} 6$ or T7 RNA polymerase. After $2 \mathrm{~h}$ of incubation at $37^{\circ} \mathrm{C}, 1.0 \mu \mathrm{l}$ DNAse (RNAse-free) was added and incubated for $15 \mathrm{~min}$ at room temperature (RT). $\left[{ }^{35} \mathrm{~S}\right.$ ]-labeled cRNA was purified with a spin column (Micro Bio-Spin P-30 Tris Spin Columns; Bio-Rad Laboratories; Hercules, CA), diluted to $100 \mu \mathrm{l}$ final volume, and $1.0 \mu \mathrm{l}$ of $1 \mathrm{M}$ dithiothreitol (DTT) was added to a final concentration of $0.01 \mathrm{M}$.

Sections were fixed with $4 \%(\mathrm{w} / \mathrm{v})$ formaldehyde for $1 \mathrm{~h}$ at RT. Next, sections were rinsed three times in $2 \times \mathrm{SSC}(300 \mathrm{mM} \mathrm{NaCl} / 30 \mathrm{mM}$ sodium citrate, $\mathrm{pH}$ 7.2) and incubated on a stir plate in $0.1 \mathrm{M}$ triethanolamine, $\mathrm{pH}$ 8.0/acetic anhydride, 1:400 (v/v) for $10 \mathrm{~min}$ at RT. Sections were then washed in $2 \times \mathrm{SSC}$ for $10 \mathrm{~min}$ at RT, and the tissue was dehydrated though graded alcohols and air-dried. $\left[{ }^{35} \mathrm{~S}\right]$-labeled riboprobe $\left(3-5 \times 10^{6} \mathrm{cpm}\right)$ was applied in $400 \mu \mathrm{l}$ of $50 \%$ formamide buffer (50\% formamide, $10 \%$ dextran sulfate, $3 \times \mathrm{SSC}, 50 \mathrm{mM} \mathrm{Na} \mathrm{HPO}_{4}, \mathrm{pH} 7.4,1 \times$ Denhardt's solution, $100 \mu \mathrm{g} / \mathrm{ml}$ yeast tRNA) with $0.1 \%$ of $1 \mathrm{M}$ DTT per each slide. The slides were then covered with glass cover slips and stored in a humidified chamber saturated with $50 \%$ formamide overnight at $55^{\circ} \mathrm{C}$ for $18 \mathrm{~h}$. Next, the cover slips were removed and the sections were washed in $2 \times \mathrm{SSC}$ for $2 \mathrm{~min}$ at $\mathrm{RT}, 2 \times$ SSC for $10 \mathrm{~min}$ at RT, and then incubated with RNAse A $(200 \mathrm{mg} / \mathrm{ml}$ in $10 \mathrm{mM}$ Tris-HCl, pH 8.0/ $0.5 \mathrm{M} \mathrm{NaCl}$ ) at $37^{\circ} \mathrm{C}$ for $30 \mathrm{~min}$. Slides were then washed at RT two times for $15 \mathrm{~min}$ in $2 \times \mathrm{SSC}$, $15 \mathrm{~min}$ in $1 \times \mathrm{SSC}, 5 \mathrm{~min}$ in $0.5 \times \mathrm{SSC}$, two times for $60 \mathrm{~min}$ in $0.1 \times \mathrm{SSC}$ at $55^{\circ} \mathrm{C}$ and $15 \mathrm{~min}$ in $0.1 \times \mathrm{SSC}$ at RT. The sections were then dehydrated in graded alcohol solutions and air-dried. Finally, the slides were placed in X-ray cassettes, apposed to film (Kodak BIOMAX MR Film, New England, Nuclear, Boston, MA), and developed after 14-60 days.

\section{Animal studies}

Adult male Sprague-Dawley rats (250 g) were used for this study. Rats received daily subcutaneous injections of haloperidol (2 $\mathrm{mg} / \mathrm{kg})$, clozapine $(20 \mathrm{mg} / \mathrm{kg})$, or vehicle for 28 consecutive days ( $N=10$ per group). Twenty-four hours following the last injection, animals were killed by decapitation, brains were rapidly removed, snap frozen in isopentane, and cryostat-sectioned $(15 \mu \mathrm{m})$ for in situ hybridization studies. 
Fig. 1. In situ hybridization using $\left[{ }^{35} \mathrm{~S}\right]-$ labeled antisense riboprobes for GPS-1, JWA, KIAA0302, and ARHGEF11 in thalamic nuclei of a representative subject. Labeling for each are seen in the anterior (A), dorsomedial (DM), centromedial (CeM), pooled ventral tier $(\mathrm{V})$, ventral anterior (VA), and reticular $(\mathrm{R})$ nuclei. Scale bar: $4 \mathrm{~mm}$.
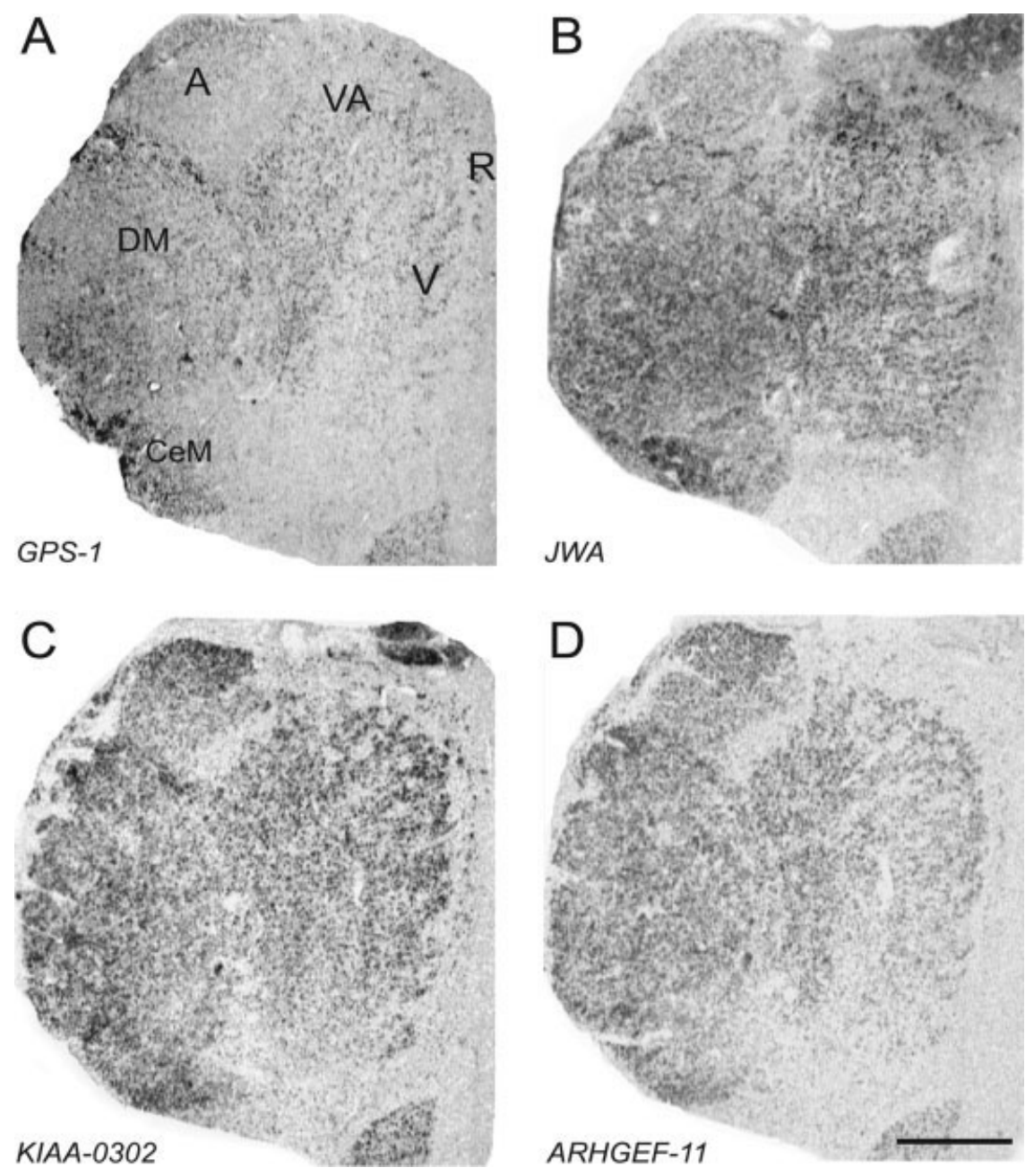

\section{Data analysis}

Images were digitized from films with a CCD camera with NIH Image software v16.1 and analyzed using Scion Image Beta 3b. Six thalamic nuclei were identified based upon cellular patterns as defined by cresyl violet staining of sections from each subject or animal. In human subjects, the following nuclei were identified: anterior (A), dorsomedial (DM), central medial $(\mathrm{CeM})$, pooled ventral tier $(\mathrm{V})$, ventral anterior, (VA), and reticular (R) nuclei. In the rat, we analyzed the paraventricular (PV), dorsomedial (DM), central medial $(\mathrm{CeM})$, pooled ventral tier $(\mathrm{V})$, and reticular ( $\mathrm{R})$ nuclei. Tissue background values were subtracted from gray scale values of each nucleus in each section and converted to optical density. Values for two sections per subject or animal were averaged and used for statistical analysis.

\section{Statistical analyses}

Correlation analysis was performed to investigate possible associations between transcript expression and age, PMI, and tissue $\mathrm{pH}$. When significant associ- ations with age, $\mathrm{pH}$, or PMI were found, analysis of covariance was utilized, otherwise analysis of variance was used, with diagnosis and nucleus as independent variables and optical density as dependent variable. Post hoc analysis was performed by Tukey's HSD. For all tests $\alpha=0.05$. Power analysis using the sample variance for the dependent measures being studied indicates that the sample size used in this work is sufficient to detect an effect.

\section{RESULTS}

Sense and antisense probes were prepared for Ajuba, GPS-1, JWA, KIAA0302, and ARHGEF11. Specific labeling was only observed for sections incubated with antisense riboprobe. We detected GPS-1, JWA, KIAA0302, and ARHGEF11 transcripts in the anterior (A), dorsomedial (DM), central medial (CeM), pooled ventral tier $(\mathrm{V})$, ventral anterior (VA), and reticular (R) thalamic nuclei (Fig. 1). We did not detect Ajuba transcripts in the thalamus by in situ hybridization.

Correlation analysis showed no association between GPS-1 and PMI. We detected significant association 
I. HUERTA ET AL.
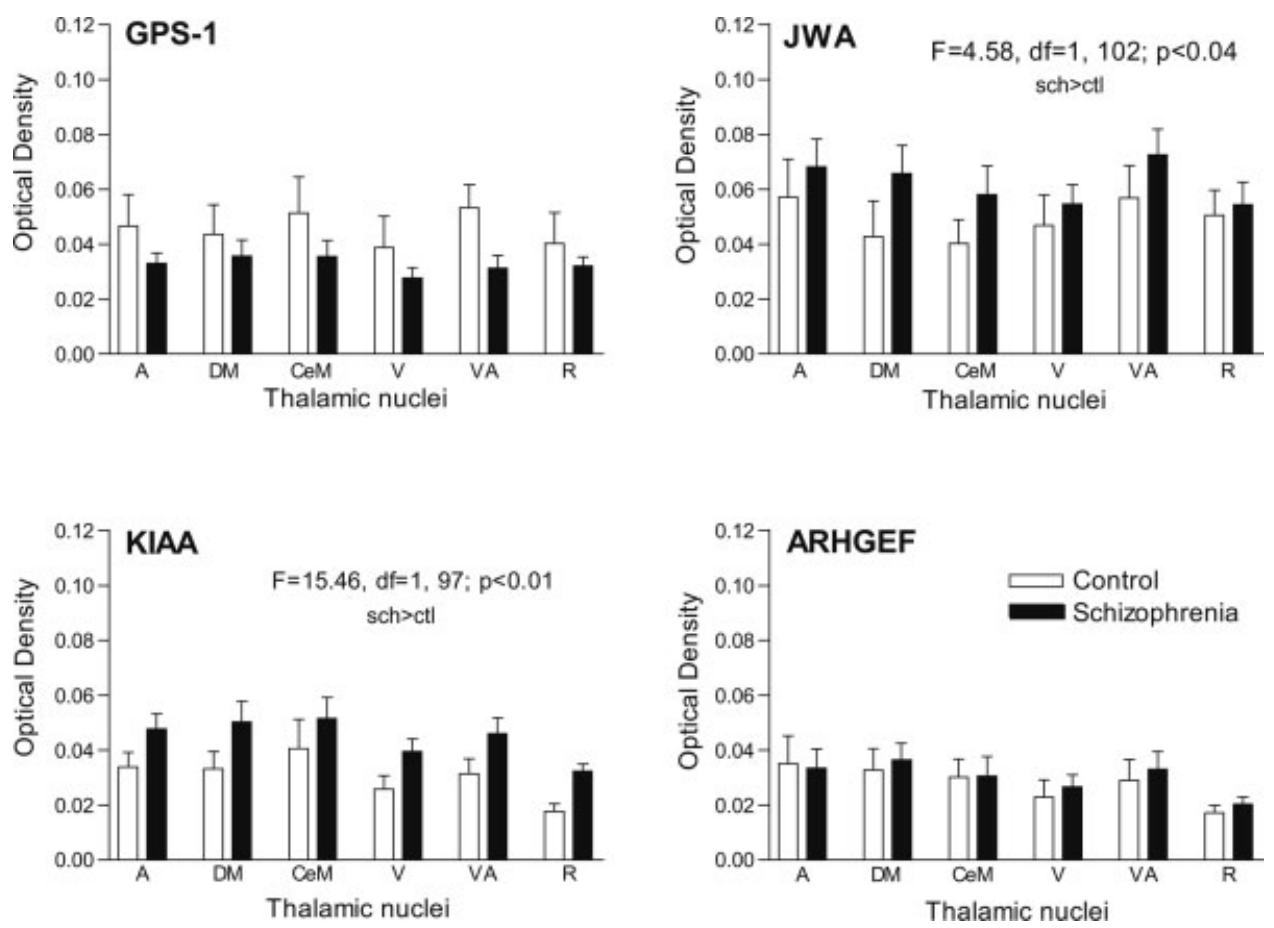

Fig. 2. GPS-1, JWA, KIAA0302, and ARHGEF11 transcript expression levels in thalamic nuclei in schizophrenia and a comparison group. Increased transcript expression was detected for JWA and KIAA0302. Anterior (A), dorsomedial (DM), centromedial (CeM), pooled ventral tier $(\mathrm{V})$, ventral anterior (VA), and reticular $(\mathrm{R})$ nuclei. between $\mathrm{pH}$ and GPS-1 expression $(r=0.439 ; P<$ $0.01)$ and between age and GPS-1 expression $(r=$ $0.27 ; P<0.01)$. There was no main effect for diagnosis, nucleus, or diagnosis by nucleus interaction for GPS-1 mRNA expression level in the thalamus, although there was a trend for GPS-1 to be reduced in schizophrenia (Fig. 2).

We did not detect significant correlations between JWA mRNA expression and age, $\mathrm{pH}$ or PMI. There was a main effect for diagnosis $(\mathrm{F}(1,102)=4.58 ; P<$ 0.04) for increased JWA mRNA levels in the thalamus in schizophrenia (Fig. 2). There was no main effect for nucleus or diagnosis by nucleus interaction.

We did not detect significant correlations between KIAA0302 mRNA expression and age, $\mathrm{pH}$ or PMI. There was a main effect for nucleus $(\mathrm{F}(5,97)=3.102$; $P<0.02)$ and diagnosis $(\mathrm{F}(1,97)=15.46 ; P<0.01)$ for increased KIAA0302 mRNA levels in the thalamus in schizophrenia, but there was not diagnosis by nucleus interaction. Post hoc analysis revealed lower KIAA0302 expression levels in the reticular nucleus when compared with those in other thalamic nuclei (Fig. 2).

Correlation analysis showed no significant association between ARHGEF11 transcript expression and age, PMI, or $\mathrm{pH}$. There was no main effect for diagnosis, nucleus, or nucleus by diagnosis interaction for thalamic expression of ARHGEF11.

Using in situ hybridization, we measured expression of these EAAT-interacting proteins in the thalami of rats treated with haloperidol, clozapine, or vehicle (Fig. 3). GPS-1, JWA, KIAA0302, and ARHGEF11 transcripts were expressed in paraventricular
(PV), dorsomedial (DM), central medial (CeM), pooled ventral tier $(\mathrm{V})$, and reticular $(\mathrm{R})$ nuclei. We did not detect significant changes in the gene expression of these molecules in rats treated with haloperidol (Fig. 3). In contrast, we did detect significant changes in rats treated with clozapine (Fig. 3). Expression of GPS-1 $(\mathrm{F}(2,90)=13.68 ; P<0.01)$ and JWA $(\mathrm{F}(2,85)$ $=3.77 ; P<0.03)$ transcripts was decreased in the thalamus of clozapine-treated rats, while KIAA0302 $(\mathrm{F}(2,90)=14.79 ; P<0.01)$ and ARHGEF11 $(\mathrm{F}(2,80)=$ 9.85; $P<0.02)$ transcript expression was increased.

\section{DISCUSSION}

We detected significant increase in the expression of EAAT-interacting proteins JWA and KIAA0302 in the thalamus in schizophrenia. No significant diagnosis by nucleus interactions was detected, suggesting that changes in JWA and KIAA0302 transcript expression involve multiple thalamic nuclei. No significant changes were detected in GPS- 1 and ARHGEF11 transcript expression in the thalamus in schizophrenia. To our knowledge, these results represent the first report of altered JWA and KIAA0302 mRNA expression in a psychiatric illness.

We found increased thalamic JWA transcript expression in schizophrenia. GTRAP3-18, the rodent isoform of JWA, downregulates glutamate uptake activity of the rat isoform of EAAT3 (called EAAC1). Increase in the expression of GTRAP3-18 does not alter EAAC1 expression levels but reduces glutamate uptake activity by altering the assembly and matura- 

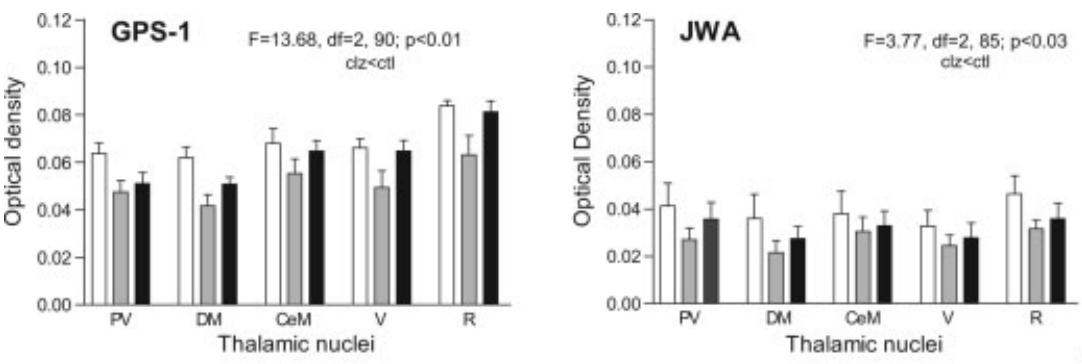

Fig. 3. GPS-1, JWA, KIAA0302, and ARHGEF11 transcript expression levels in the thalamic nuclei in antipsychotic-treated rats and a control group. Significant changes were only observed in clozapine-treated rats (decreased GPS-1 and JWA, increased KIAA0302 and ARHGEF11), but not in haloperidol-treated rats. Paraventricular (PV), dorsomedial $(\mathrm{DM})$, centromedial $(\mathrm{CeM})$, pooled ventral tier $(\mathrm{V})$, and reticular $(\mathrm{R})$ nuclei.
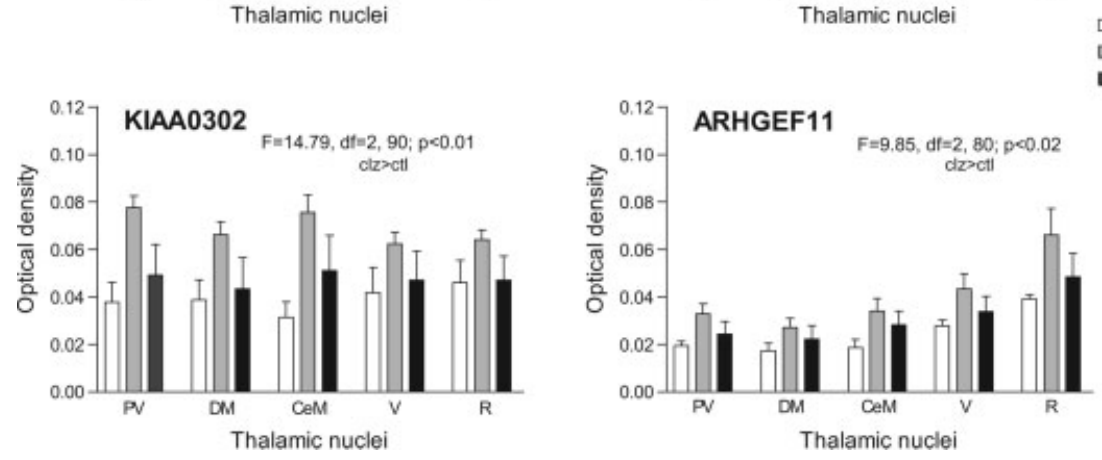

tion of EAAC1 subunits within the endoplasmic reticulum (Jackson et al., 2001; Ruggiero et al., 2003). Interestingly, we previously did not detect changes in EAAT3 mRNA expression in the thalamus in schizophrenia in the same cohort of subjects (Smith et al., 2001a). Taken together, an increase in transcript expression of a putative inhibitor of EAAT3 with no changes in total EAAT3 mRNA expression might be consistent with a decrease in EAAT3 function in the thalamus in schizophrenia.

We also found increased expression of KIAA0302 in the thalamus in schizophrenia. KIAA0302 is a $\beta$-spectrin that is associated with intracellular trafficking in glutamate synapses that facilitates EAAT4-mediated glutamate reuptake. Previous studies have demonstrated that KIAA0302 directly interacts with EAAT4. However, while EAAT4 is only highly expressed in the cerebellum and we were previously unable to detect EAAT4 mRNA in the thalamus, KIAA0302 is highly expressed throughout the brain (unpublished observation) (Smith et al., 2001a). This divergent expression of EAAT4 and its associated interacting protein suggests that KIAA0302 might regulate other EAATs and have different functional roles in glutamate synapses. For example, KIAA0302 might bind other glutamate transporters to the cytoskeleton via $\alpha$-actin, a potentially important mechanism since recent studies have indicated a role for the actin network in glial glutamate transporter clustering (Zhou and Sutherland, 2004).

We did not detect changes in GPS-1 mRNA expression in the thalamus in schizophrenia. Previously, we have found increased expression of glial glutamate transporters EAAT1 and EAAT2 in the thalamus in schizophrenia (Smith et al., 2001a). Since GPS-1 down- regulates glial glutamate reuptake, our data are consistent with an increase in EAAT2-mediated glutamate reuptake capacity in the thalamus, suggesting that glutamate synapses have increased levels of glutamate in schizophrenia.

Abnormalities in the expression of EAAT-associated molecules in the thalamus were limited to molecules reported to modulate neuronal (JWA and KIAA0302), and not glial (GPS-1, Ajuba), EAATs. Interestingly, changes in transcript expression for the EAATs themselves are limited to glial (EAAT1 and EAAT2), and not neuronal (EAAT3), transporters. These data are consistent with reported differences in the regulation of glial and neuronal glutamate transporters. For example, previous studies have reported that arachidonic acid inhibits EAAT1 and EAAT2-mediated glutamate reuptake, while it increases EAAT3 reuptake activity (Volterra et al., 1994). Furthermore, protein kinases differentially regulate cell surface expression and activity of glial and neuronal glutamate transporters (Guillet et al., 2005). Activation of PKC rapidly increases cell surface expression of EAAT3 (Fournier et al., 2004), but cell surface expression of EAAT2 is decreased after PKC activation (Kalandadze et al., 2002). Interestingly, in contrast to EAAT1 and EAAT2, EAAT3 is rapidly mobilized to the cell surface from a large intracellular pool (Robinson, 2002). Our data are consistent with cell-subtypespecific regulation of neuronal and glial-based EAATs and suggest that abnormalities of neuronal EAAT function in schizophrenia may be associated with alterations in the expression of specific EAAT regulatory proteins.

Differences in the regulation of glial and neuronal transporters may be related to their distinct roles in 
glutamate synapses. Glial transporters make the largest contribution to glutamate uptake at excitatory synapses, while the neuronal transporters might clear glutamate from specific compartments and play an important role in limiting glutamate spillover leading to activation of receptors at neighboring synapses (Diamond, 2001; Huang and Bergles, 2004). Glutamate spillover could enhance the induction of LTP in adjacent synapses, possibly modulating synapse specificity (Diamond, 2001). Moreover, induction of LTP was associated with an increase in surface expression and activity of EAAC1 (the rat homologue of EAAT3) (Levenson et al., 2002), suggesting a role for neuronal EAATs in the regulation of synaptic plasticity. Thus, increased transcript expression of JWA in the thalamus in schizophrenia could indicate a decrease in EAAT3 surface expression and activity, resulting in alterations in the contributions of postsynaptic glutamate transporters to the regulation of LTP and other molecular substrates of neuroplasticity. Finally, increased expression of glial EAAT transcripts in the thalamus in schizophrenia (Smith et al., 2001a) may be consistent with increased glutamate reuptake capacity, in response to a possible increase in glutamate release in the thalamus in this illness (Moghaddam and Adams, 1998; Moghaddam et al., 1997).

Antipsychotic medications are known to influence glutamate neurotransmission (De Souza et al., 1999; Melone et al., 2001; Schneider et al., 1998). In this study, in rats treated for 4 weeks with clozapine, but not haloperidol, we found decreases in thalamic expression of GPS-1 and JWA, and increased expression of ARHGEF11 and KIAA0302. Since the subjects included in this study were generally treated with typical (similar to haloperidol) but not atypical (similar to clozapine) antipsychotics, and haloperidol did not affect transcript expression of EAAT-interacting proteins in the rat thalamus, the changes we observed in schizophrenia are likely not associated with antipsychotic drug treatment. While there are no previous reports on the effects of antipsychotics on the expression of EAAT-interacting proteins, recent studies in rats treated with haloperidol, have shown decreased gene expression on glial and neuronal glutamate transporters in the cortex (Schmitt et al., 2003). Another study reported typical and atypical antipsychotic reduced glutamate uptake from rat prefrontal cortex (Vallejo-Illarramendi et al., 2005; Yang and Wang, 2005). It is not known whether these findings can be extended to the thalamus. Our findings of decreased GPS-1 and JWA and increased KIAA0302 and ARHGEF11 are apparently contradictory to reports of decreased glutamate reuptake with clozapine, since these changes in mRNA expression would theoretically increase glutamate reuptake. Difference in dose, route, and duration of treatment as well as the regions examined may account for these inconsis- tent findings. The apparent selectivity of atypical antipsychotics for the regulation of EAAT-interacting proteins suggests that the unique properties and side effect profile for atypical medications such as clozapine may be the basis for the differential regulation of glutamate reuptake activity by typical vs. atypical antipsychotics.

There are several potential limitations of this study. One limitation is the advanced age of the subjects. Age-related changes in glutamatergic gene expression could make it more difficult to detect subtle, diseasespecific alterations, and older schizophrenics have higher lifetime exposures to antipsychotics when compared with subjects in younger cohorts. However, we have previously detected robust changes in glutamate receptor transcripts, proteins, and binding sites in a similar cohort of these aged schizophrenics when compared with those in normal controls, clearly demonstrating the persistence of detectable changes in gene expression in older subjects (Bruneau et al., 2005; Clinton et al., 2003; Smith et al., 2001a,b). Further, we have found striking differences in glutamatergic gene expression in middle aged (from the Stanley Foundation) vs. elderly subjects, indicating that expression of glutamatergic markers that are abnormal in middle age may not necessarily continue to show the same abnormality in older age (Clinton et al., 2003; Clinton and Meador-Woodruff, 2004). Thus, pooling subjects of various ages in such studies may be counterproductive. On the other hand, the advanced age of our subjects may be a strength of this cohort, since the subjects are free from confounds such as suicide and substance abuse. In addition, our elderly cohort is rigorously characterized ante mortem and has a predominance of negative symptomatology and cognitive impairment commonly found in the later stages of schizophrenia, providing a more homogenous sample with a level of reliability of diagnostic and demographic variables that are difficult to achieve in this field.

Another concern is that our findings only indicate whether or not there was a change in total EAATinteracting proteins transcript expression and do not specify whether changes were in all cells expressing these transcripts or in a subset of cells. Finally, changes in transcript expression do not necessarily indicate a change in protein expression or function. For example, there may also be changes in levels of protein expression, localization of proteins within the cell, as well as linkage of interacting proteins to transporters or intracellular signaling machinery.

The glutamate hypothesis of schizophrenia is based on the observation that NMDA receptor antagonists such as PCP can precipitate schizophreniform symptoms in nonpsychotic subjects. These effects may be secondary to alterations in synaptic glutamate levels since administration of PCP into the rat prefrontal 
cortex increased glutamate efflux (Moghaddam and Adams, 1998). Consistent with perturbations of glutamate transmission in schizophrenia, we have previously described deficits in NMDA receptor subunits and binding sites, as well as increased expression of plasma membrane (EAAT1, EAAT2) and vesicular (VGLUT2) glutamate transporter transcripts in the thalamus in schizophrenia (Ibrahim et al., 2000a,b; Meador-Woodruff et al., 2003; Smith et al., 2001a,b). The data from the present study suggest that alterations in glutamate transmission in schizophrenia involve not only glutamate receptors and transporters, but also intracellular molecules that link the transporters to signaling pathways and the cytoskeleton.

In summary, we measured transcript expression of neuronal (JWA, KIAA0302, and ARHGEF11) and glial (GPS-1) EAAT-interacting proteins in the thalamus in schizophrenia. Our findings of increased thalamic JWA and KIAA0302 transcript expression suggest that changes in EAAT-interacting proteins are limited to molecules interacting with neuronal, and not glial, glutamate transporters. In contrast, changes in EAAT thalamic transcript expression are limited to glial (EAAT1 and EAAT2), and not neuronal (EAAT3), transporters. This study supports the hypothesis of excessive glutamatergic neurotransmission in the thalamus in schizophrenia, and suggests that the EAAT-interacting proteins may be high-yield substrates to target for the development of novel treatment modalities for this devastating illness.

\section{ACKNOWLEDGMENTS}

This work was supported by MH70895 (JHMW), a Pfizer Postdoctoral Fellowship (REM), VA Merit Review (VH), and MH064673 (VH).

\section{REFERENCES}

Andreasen NC, O'Leary DS, Cizadlo T, Arndt S, Rezai K, Ponto LL Watkins GL, Hichwa RD. 1996. Schizophrenia and cognitive dysmetria: a positron-emission tomography study of dysfunctional prefrontal-thalamic-cerebellar circuitry. Proc Natl Acad Sci USA 93:9985-9990.

Bellocchio EE, Reimer RJ, Fremeau RT, Jr, Edwards RH. 2000 Uptake of glutamate into synaptic vesicles by an inorganic phosphate transporter [see comments]. Science 289:957-960.

Bruneau EG, McCullumsmith RE, Haroutunian V, Davis KL, Meador-Woodruff JH. 2005. Increased expression of glutaminase and glutamine synthetase mRNA in the thalamus in schizophrenia Schizophr Res 75:27-34

Buchsbaum MS, Hazlett EA. 1998. Positron emission tomography studies of abnormal glucose metabolism in schizophrenia. Schiz ophr Bull 24:343-364.

Buchsbaum MS, Someya T, Teng CY, Abel L, Chin S, Najafi A, Haier RJ, Wu J, Bunney WE, Jr. 1996. PET and MRI of the thalamus in never-medicated patients with schizophrenia. Am J Psychiatry 153:191-199.

Butchbach ME, Guo H, Lin CL. 2003. Methyl- $\beta$-cyclodextrin but not retinoic acid reduces EAAT3-mediated glutamate uptake and increases GTRAP3-18 expression. J Neurochem 84:891-894.

Byne W, Buchsbaum MS, Mattiace LA, Hazlett EA, Kemether E, Elhakem SL, Purohit DP, Haroutunian V, Jones L. 2002. Postmortem assessment of thalamic nuclear volumes in subjects with schizophrenia. Am J Psychiatry 159:59-65.
Clinton SM, Haroutunian V, Davis KL, Meador-Woodruff JH. 2003. Altered transcript expression of NMDA Receptor-associated postsynaptic proteins in the thalamus of subjects with schizophrenia. Am J Psychiatry 160:1100-1109.

Clinton SM, Meador-Woodruff JH. 2004. Thalamic dysfunction in schizophrenia: neurochemical, neuropathological, and in vivo imaging abnormalities. Schizophr Res 69(2/3):237-253.

Danbolt NC. 2001. Glutamate uptake. Prog Neurobiol 65:1-105.

Danos P, Baumann B, Kramer A, Bernstein HG, Stauch R, Krell D, Falkai P, Bogerts B. 2003. Volumes of association thalamic nuclei in schizophrenia: a postmortem study. Schizophr Res 60(2/3):141155.

De Souza IE, McBean GJ, Meredith GE. 1999. Chronic haloperidol treatment impairs glutamate transport in the rat striatum. Eur J Pharmacol 382:139-142.

Diamond JS. 2001. Neuronal glutamate transporters limit activation of NMDA receptors by neurotransmitter spillover on CA1 pyramidal cells. J Neurosci 21:8328-8338.

Dorph-Petersen KA, Pierri JN, Sun Z, Sampson AR, Lewis DA. 2004. Stereological analysis of the mediodorsal thalamic nucleus in schizophrenia: volume, neuron number, and cell types. J Comp Neurol 472:449-462.

Fournier KM, Gonzalez MI, Robinson MB. 2004. Rapid trafficking of the neuronal glutamate transporter, EAAC1: evidence for distinct trafficking pathways differentially regulated by protein kinase $\mathrm{C}$ and platelet-derived growth factor. J Biol Chem 279:34505-34513.

Guillet BA, Velly LJ, Canolle B, Masmejean FM, Nieoullon AL, Pisano P. 2005. Differential regulation by protein kinases of activity and cell surface expression of glutamate transporters in neuron-enriched cultures. Neurochem Int 46:337-346.

Harrison PJ, Law AJ, Eastwood SL. 2003. Glutamate receptors and transporters in the hippocampus in schizophrenia. Ann NY Acad Sci 1003:94-101.

Hazlett EA, Buchsbaum MS, Byne W, Wei TC, Spiegel-Cohen J, Geneve C, Kinderlehrer R, Haznedar MM, Shihabuddin L, Siever LJ. 1999. Three-dimensional analysis with MRI and PET of the size, shape, and function of the thalamus in the schizophrenia spectrum. Am J Psychiatry 156:1190-1199.

Hollmann M, Heinemann S. 1994. Cloned glutamate receptors. Annu Rev Neurosci 17:31-108.

Huang YH, Bergles DE. 2004. Glutamate transporters bring competition to the synapse. Curr Opin Neurobiol 14:346-352.

Ibrahim HM, Healy DJ, Hogg AJ, Jr, Meador-Woodruff JH. 2000a. Nucleus-specific expression of ionotropic glutamate receptor subunit mRNAs and binding sites in primate thalamus. Brain Res Mol Brain Res 79(1/2):1-17.

Ibrahim HM, Hogg AJ, Healy DJ, Haroutunian V, Davis KL, Meador-Woodruff JH. 2000b. Ionotropic glutamate receptor binding and subunit mRNA expression in thalamic nuclei in schizophrenia. Am J Psychiatry 157:1811-1823.

Itil T, Keskiner A, Kiremitci N, Holden JM. 1967. Effect of phencyclidine in chronic schizophrenics. Can Psychiatr Assoc J 12:209212.

Jackson M, Song W, Liu MY, Jin L, Dykes-Hoberg M, Lin CI, Bowers WJ, Federoff HJ, Sternweis PC, Rothstein JD. 2001. Modulation of the neuronal glutamate transporter EAAT4 by two interacting proteins. Nature 410:89-93.

Kalandadze A, Wu Y, Robinson MB. 2002. Protein kinase C activation decreases cell surface expression of the GLT-1 subtype of glutamate transporter. Requirement of a carboxyl-terminal domain and partial dependence on serine 486. J Biol Chem 277:4574145750 .

Kanai Y, Smith CP, Hediger MA. 1993. A new family of neurotransmitter transporters: the high-affinity glutamate transporters. Faseb J 7:1450-1459.

Lahti AC, Holcomb HH, Medoff DR, Tamminga CA. 1995. Ketamine activates psychosis and alters limbic blood flow in schizophrenia. Neuroreport 6:869-872.

Levenson J, Weeber E, Selcher JC, Kategaya LS, Sweatt JD, Eskin A. 2002. Long-term potentiation and contextual fear conditioning increase neuronal glutamate uptake. Nat Neurosci 5:155-161.

Lewis DA, Glantz LA, Pierri JN, Sweet RA. 2003. Altered cortical glutamate neurotransmission in schizophrenia: evidence from morphological studies of pyramidal neurons. Ann NY Acad Sci 1003:102-112.

Lin CI, Orlov I, Ruggiero AM, Dykes-Hoberg M, Lee A, Jackson M, Rothstein JD. 2001. Modulation of the neuronal glutamate transporter EAAC1 by the interacting protein GTRAP3-18. Nature 410:84-88.

Luby E, Gottlieb J, Cohen B, Rosenbaum G, Domino E. 1962. Model psychoses and schizophrenia. Am J Psychiatry 119:61-67. 
Marie H, Billups D, Bedford FK, Dumoulin A, Goyal RK, Longmore GD, Moss SJ, Attwell D. 2002. The amino terminus of the glial glutamate transporter GLT-1 interacts with the LIM protein Ajuba. Mol Cell Neurosci 19:152-164.

Meador-Woodruff JH, Clinton SM, Beneyto M, McCullumsmith RE 2003. Molecular abnormalities of the glutamate synapse in the thalamus in schizophrenia. Ann NY Acad Sci 1003:75-93.

Melone M, Vitellaro-Zuccarello L, Vallejo-Illarramendi A, Perez-Samartin A, Matute C, Cozzi A, Pellegrini-Giampietro DE, Rothstein JD, Conti F. 2001. The expression of glutamate transporter GLT-1 in the rat cerebral cortex is down-regulated by the antipsychotic drug clozapine. Mol Psychiatry 6:380-386.

Moghaddam B, Adams BW. 1998. Reversal of phencyclidine effects by a group II metabotropic glutamate receptor agonist in rats. Science 281:1349-1352.

Moghaddam B, Adams B, Verma A, Daly D. 1997. Activation of glutamatergic neurotransmission by ketamine: a novel step in the pathway from NMDA receptor blockade to dopaminergic and cognitive disruptions associated with the prefrontal cortex. J Neurosci 17:2921-2927.

Pakkenberg B. 1992. The volume of the mediodorsal thalamic nucleus in treated and untreated schizophrenics. Schizophr Res 7:95-100.

Popken GJ, Bunney WE, Jr, Potkin SG, Jones EG. 2000. Subnucleus-specific loss of neurons in medial thalamus of schizophrenics. Proc Natl Acad Sci USA 97:9276-9280.

Robinson MB. 2002. Regulated trafficking of neurotransmitter transporters: common notes but different melodies. J Neurochem 80:1-11.

Rothstein JD, Martin L, Levey AI, Dykes-Hoberg M, Jin L, Wu D, Nash N, Kuncl RW. 1994. Localization of neuronal and glial glutamate transporters. Neuron 13:713-725.

Ruggiero A, Vidensky S, Rothstein JD. 2003.GTRAP3-18 protein is able to regulate the activity of excitatory amino acid transporters through alterations in ASN linked glycosyl processing. Abstract viewer, Society for Neuroscience: Program No. 372 315 .
Scarr E, Beneyto M, Meador-Woodruff JH, Deans B. 2005. Cortical glutamatergic markers in schizophrenia. Neuropsychopharmacology 30:1521-1531.

Schmitt A, Zink M, Petroianu G, May B, Braus DF, Henn FA. 2003. Decreased gene expression of glial and neuronal glutamate transporters after chronic antipsychotic treatment in rat brain. Neurosci Lett 347:81-84.

Schneider JS, Wade T, Lidsky TI. 1998. Chronic neuroleptic treatment alters expression of glial glutamate transporter GLT-1 mRNA in the striatum. Neuroreport 9:133-136.

Smith RE, Haroutunian V, Davis KL, Meador-Woodruff JH. 2001a. Expression of excitatory amino acid transporter transcripts in the thalamus of subjects with schizophrenia. Am J Psychiatry 158: 1393-1399.

Smith RE, Haroutunian V, Davis KL, Meador-Woodruff JH. 2001b. Vesicular glutamate transporter transcript expression in the thalamus in schizophrenia. Neuroreport 12:2885-2887.

Vallejo-Illarramendi A, Torres-Ramos M, Melone M, Conti F, Matute C. 2005. Clozapine reduces GLT-1 expression and glutamate uptake in astrocyte cultures. Glia 50:276-279.

Volterra A, Trotti D, Racagni G. 1994. Glutamate uptake is inhibited by arachidonic acid and oxygen radicals via two distinct and additive mechanisms. Mol Pharmacol 46:986-992.

Watanabe M, Robinson MB, Kalandadze A, Rothstein JD. 2003. GPS1, interacting protein with GLT-1. Program No. 37216 2003, SfN Abstract.

Watanabe M, Ueki T, Jackson M, Ruggiero AM, Sawa A, Kalandadze A, Robinson MB, Rothstein JD. 2004. CSN1 Downregulates GLT-1 activity. Program No. 1688 2004, SfN Abstract.

Yang TT, Wang SJ. 2005. Effects of haloperidol and clozapine on glutamate release from nerve terminals isolated from rat prefrontal cortex. Synapse 56:12-20.

Young KA, Manaye KF, Liang C, Hicks PB, German DC. 2000. Reduced number of mediodorsal and anterior thalamic neurons in schizophrenia. Biol Psychiatry 47:944-953.

Zhou J, Sutherland ML. 2004. Glutamate transporter cluster formation in astrocytic processes regulates glutamate uptake activity. J Neurosci 24:6301-6306. 